\title{
KARAKTERISTIK DAN AKTIVITAS ANTIOKSIDAN SABUN PADAT TRANSPARAN YANG DIPERKAYA DENGAN EKSTRAK KASAR KAROTENOID Chlorella pyrenoidosa
}

\section{Characteristics and Antioxidant Activity from Transparent Solid Soap Enriched with Carotenoid Crude Extract of Chlorella pyrenoidosa}

\author{
Ni Wayan Sri Agustini ${ }^{1 *}$ dan Agustina H. Winarni ${ }^{2}$ \\ ${ }_{1}$ Pusat Penelitian Bioteknologi - Lembaga IImu Pengetahuan Indonesia (LIPI), \\ Jl. Raya Bogor No.507, Nanggewer Mekar, Cibinong, Bogor, Jawa Barat \\ ${ }^{2}$ Institut Sains dan Teknologi Nasional, Jalan Moh Kahfi II, Srengseng Sawah, Jagakarsa, Jakarta Selatan, DKI Jakarta \\ *Korespondensi Penulis: wayan_sa2002@yahoo.com
}

Diterima: 15 Januari 2017; Disetujui: 29 Maret 2017

\begin{abstract}
ABSTRAK
Sabun berfungsi membersihkan kulit, tidak merusak kulit serta mampu melindungi kulit dari efek radikal bebas. Senyawa yang mampu menangkal radikal bebas adalah antioksidan yang antara lain bersumber dari Chlorella pyrenoidosa. Tujuan dari penelitian ini adalah untuk mengetahui aktivitas antioksidan dari ekstrak kasar karotenoid $C$. pyrenoidosa yang diformulasikan pada sabun padat transparan dan karakteristik sabun yang dihasilkan. Konsentrasi ekstrak kasar karotenoid yang digunakan adalah $5 \%, 10 \%$ dan $15 \%$. Sabun padat transparan dibuat dengan metode setengah panas (semi-boiled). Evaluasi sediaan meliputi warna, kekerasan sabun, $\mathrm{pH}$, kadar air, asam lemak bebas, lemak tidak tersabunkan, aktivitas antioksidan dan daya stabilitas sabun pada penyimpanan suhu $25-30{ }^{\circ} \mathrm{C}$ dan $60^{\circ} \mathrm{C}$ selama 3 minggu. Hasil studi menunjukkan bahwa sabun padat transparan yang mengandung ekstrak kasar karotenoid sebanyak 5\%, 10\%, dan $15 \%$ memiliki aktivitas antioksidan dengan nilai $I_{50}$ berturut-turut sebesar $66,42 \mu \mathrm{g} / \mathrm{ml}$, $59,18 \mu \mathrm{g} / \mathrm{ml}$, dan $10,21 \mu \mathrm{g} / \mathrm{ml}$. Sabun padat transparan dengan kandungan ekstrak kasar karotenoid sebanyak $5 \%$ berwarna kuning neon carrot, ekstrak $10 \%$ berwarna kuning pizzaz dan ekstrak $15 \%$ berwarna kuning pumpkin. Seluruh sabun beraroma lemongrass. Sabun padat transparan memiliki nilai pH sebesar 9,31-10,47, kadar air 14,45-16,28\%, kekerasan sabun 1,40-1,81 mm/ detik, jumlah asam lemak bebas $0,42-0,68 \%$ dan lemak tidak tersabunkan 1,79-1,84\%. Berdasarkan hasil uji stabilitas, sabun tahan disimpan dalam suhu kamar selama 2 tahun, karena sabun relatif stabil pada penyimpanan suhu $60^{\circ} \mathrm{C}$ selama 3 minggu.
\end{abstract}

\section{KATAKUNCI : Chlorella pyrenoidosa, ekstrak kasar karotenoid, sabun padat transparan, antioksidan}

\begin{abstract}
Soap was used to clean the skin but not damage the skin and able to protect skin from free radical effect. The compounds that could counteract free radical are antioxidants which can be found in Chlorella pyrenoidosa. The aims of this research were to determine the characteristic of soap and the antioxidant activity of $\underline{C}$. pyrenoidosa carotenoids crude extract that was formulated in transparent solid soap. The carotenoid crude extract concentrations were $5 \%, 10 \%$, and $15 \%$. The transparent solid soap was made using semi-boiled methods. The transparent solid soap were evaluated for color, soap solidity, $\mathrm{pH}$, water content, free fatty acid content, unsaturated fatty acid content, antioxidant activity and soap stability at $25-30{ }^{\circ} \mathrm{C}$ and $60{ }^{\circ} \mathrm{C}$ in 3 weeks storage. The study showed that transparent solid soaps containing $5 \%, 10 \%$ and $15 \%$ carotenoid crude extracts had antioxidant activity with $I C_{50}$ value of $66.42 \mu \mathrm{g} / \mathrm{ml}, 59.18 \mu \mathrm{g} / \mathrm{ml}$ and $10.21 \mu \mathrm{g} / \mathrm{ml}$ respectively. Transparent solid soap with 5\% carotenoid extract appeared in neon carrot yellow color, $10 \%$ extract appeared in pizzaz yellow color and 15\% extract apperared in pumpkin yellow color. Soaps had lemongrass odor. Transparent solid soap had $\mathrm{pH}$ value of 9.31-10.47, water content of 14.45$16.28 \%$, soap hardness of $1.40-1.81 \mathrm{~mm} / \mathrm{sec}$, amount of free fatty acid $0.42-0.68 \%$ and unsaponified fat $1.79-1.84 \%$. Based on the stability test results, the soap could be stored for 2 years at room temperature because the soap was relatively stable at storage temperature of $60{ }^{\circ} \mathrm{C}$ for 3 weeks.
\end{abstract}

KEYWORDS: Chlorella pyrenoidosa, carotenoid crude extract, transparent solid soap, antioxidant 


\section{PENDAHULUAN}

Meningkatnya kebutuhan dan semakin beragamnya selera masyarakat, menyebabkan produk sabun pembersih tubuh kini sudah sangat bervariasi seperti sabun cair, sabun opaque dan sabun padat transparan. Sabun padat transparan merupakan salah satu inovasi produk kosmetik, pembersih tubuh yang dapat menjadikan sabun menjadi lebih menarik dengan daya tembus pandang, menghasilkan busa lebih lembut, serta kenampakan lebih berkilau dibandingkan dengan jenis sabun lainnya.

Sabun yang baik bukan hanya dapat membersihkan kulit dari kotoran saja, tetapi juga memiliki kandungan zat yang tidak merusak kulit serta dapat melindungi kulit, salah satunya adalah dari efek radikal bebas. Efek radikal bebas pada kulit ditandai dengan adanya keriput sehingga kulit cepat mengalami proses penuaan, adanya noda hitam, telihat lebih kusam, kering, bahkan dapat menimbulkan kanker kulit. Senyawa yang dapat menangkal radikal bebas adalah antioksidan. Antioksidan secara nyata mampu memperlambat atau menghambat oksidasi zat yang mudah teroksidasi meskipun dalam konsentrasi rendah (Green, 2008). Sumber antioksidan dapat berasal dari senyawa sintetis maupun alami. Senyawa antioksidan alami lebih direkomendasikan penggunaannya karena memiliki tingkat keamanan yang lebih baik sehingga pemanfaatannya lebih luas dalam bidang kesehatan dan kosmetika (Brewer, 2011).

Salah satu jenis antioksidan alami yaitu karotenoid. Karotenoid adalah pigmen terpenoid berwarna kuning hingga oranye-merah dan disintesis oleh organisme fotosintetik seperti mikroalga. Ada dua kelompok besar karotenoid yaitu xantofil (karotenoid yang membawa atom oksigen)dan karotena (karotenoid yang murni hidrokarbon, tidak memiliki atom oksigen). Salah satu jenis mikroalga yang menghasilkan senyawa karotenoid adalah Chlorella pyrenoidosa yang merupakan mikroalga bersel tunggal dari kelas Chlorophyceae. Mikroalga ini diketahui sebagai penghasil bermacam jenis karotenoid seperti lutein, $\beta$ - karoten, $\alpha$-karoten, neoxanthin, zeaxanthin dan astaxanthin (Stephen Inbaraj, Chien, \& Chen, 2006). Goiris et al., (2012), mengemukakan bahwa senyawa fenol dan karotenoid dari beberapa jenis mikrolaga memiliki kapasitas antioksidan yang tinggi sehingga bisa menjadi sumber antioksidan alami yang potensial.

Manfaat karotenoid dalam bidang kosmetika, dilaporkan dapat berfungsi sebagai pelembab, menghaluskan, menjaga elastisitas kulit, mencegah keriput, garis-garis halus, bintik-bintik hitam pada kulit serta sebagai antioksidan yang dapat menangkal radikal bebas yang dapat merusak kesehatan tubuh (Kusmiati, Agustini, Tamat, \& Rawati, 2010). Penambahan karotenoid ini dapat diformulasikan pada body lotion moisturizer cream pelembab dan sabun padat ataupun cair. Penambahan karotenoid ke dalam formulasi sabun padat transparan diharapkan mampu melindungi kulit dari radikal bebas yang masuk melalui permukaan kulit karena sabun padat transparan merupakan salah satu sediaan emulsi yang difungsikan sebagai penghantar obat pada kulit.

Berdasarkan uraian diatas, maka penelitian ini dilakukan untuk mengetahui aktivitas antioksidan ekstrak pigmen karotenoid dari C. pyrenoidosa yang diformulasikan pada sabun padat transparan serta karakteristik sabunnya.

\section{BAHAN DAN METODE}

\section{Bahan}

Penelitian ini dilakukan pada bulan Mei-November 2015 di Pusat Penelitian Bioteknologi-LIPI, menggunakan mikroalga jenis $C$. pyrenoidosa yang merupakan koleksi dari Laboratorium Mikroalga Air Tawar, Puslit Bioteknologi-LIPI. Pertumbuhan C. pyrenoidosa menggunakan medium Modified Bristol Medium (MBM) (Agustini \& Kabinawa, 1997). Bahan pembuatan sabun tertera pada Tabel 1. Peralatan yang digunakan untuk kultivasi $C$. pyrenoidosa, ekstraksi karotenoid, serta pembuatan dan evaluasi sabun adalah botol kultur, lampu TI 40 watt, blower (Resun), homogenizer (WiseTis), spektrofotometri UV-Vis (Hitachi U-3900), sentrifuse (Hitachi sentrifuge), timbangan analitik (Precise $40 \mathrm{sm}-200 \mathrm{~A}$ ), $\mathrm{pH}$ meter (Eutech Instruments), penetrometer (Kochler), inkubator (Memmert) dan peralatan lainnya.

\section{Metode}

\section{Kultivasi mikroalga C. pyrenoidosa}

Chlorella pyrenoidosa dikultivasi pada botol ukuran 2 L menggunakan media MBM (Modified Bristol Medium). Kultur diberi aerasi secara terus menerus menggunakan blower, intensitas cahaya 2500 lux dan pH 7,0. Kepadatan sel diukur dengan metoda turbidimetri menggunakan Spektrofotometer UV-Vis pada panjang gelombang $550 \mathrm{~nm}$ (Becker, 1994). Pemanenan dilakukan pada fase stasioner awal (hari ke 8) menggunakan sentrifuse (Hitachi, Himac CT GEL) pada kecepatan 6000 rpm selama 10 menit.

\section{Ekstraksi pigmen karotenoid.}

Pigmen karotenoid diekstraksi menggunakan metoda Hua-Bin, Jiang dan Cheng (2002). Biomassa 
basah disuspensikan dengan $\mathrm{KOH} 10 \mathrm{M}$ kemudian dipanaskan pada suhu $60^{\circ} \mathrm{C}$ selama 10 menit. Setelah dingin, suspensi tersebut ditambahkan dengan diklorometan dan disentrifuse. Fraksi karotenoid yang berwarna kuning dikumpulkan. Proses ini dilakukan secara berulang hingga fraksi berwarna kuning yang dihasilkan menjadi berwarna kuning pucat. Setelah itu, fraksi berwarna kuning dikeringkan di atas penangas pada suhu $40^{\circ} \mathrm{C}$ sehingga didapatkan hasil ekstrak kasar karotenoid. Ekstrak kasar karotenoid ditimbang dan dihitung berat keringnya dengan cara gravimetri.

\section{Pembuatan sediaan sabun padat transparan}

Sabun padat transparan dibuat dengan formulasi menurut Cognis (2003) yang telah termodifikasi. Modifikasi dilakukan pada penggantian minyak nabati dengan minyak zaitun, minyak jarak dan minyak kelapa serta penambahan metil paraben dan propil paraben seperti terlihat pada Tabel 1. Penggunaan minyak berfungsi untuk memberikan kejernihan sabun, etanol $96 \%$ untuk melarutkan sabun agar lebih transparan, gliserin dan sukrosa $50 \%$ sebagai humectant dan untuk meningkatkan kekerasan sabun, trietanolamin sebagai emulsifier dan surfaktan sedangkan metilparaben dan propil paraben berfungsi sebagai anti jamur. Sebelum melakukan penelitian ini terlebih dahulu dilakukan uji penelitian pendahuluan dengan menggunakan penambahan konsentrasi ekstrak kasar karotenoid yang lebih rendah dari $5 \%$, namun hasil yang diperoleh tidak menunjukkan adanya aktivitas antioksidan. Oleh karena itu, pada studi ini penambahan ekstrak kasar karotenoid dilakukan dengan variasi konsentrasi sebesar $5 \%$, $10 \%$ dan $15 \%$.

Pada tahap awal pembuatan sabun, terlebih dahulu dilakukan penentuan kecepatan dan waktu pengadukan optimum sehingga menghasilkan sediaan sabun padat transparan yang homogen. Kecepatan pengadukan yang diterapkan adalah 250, 350 dan 400 rpm dengan waktu masing-masing 10, 20 dan 30 menit.

Proses pembuatan sabun diawali dengan mereaksikan asam stearat dalam minyak zaitun, minyak kelapa, minyak jarak dan butil hidroksitoluen (yang telah dilarutkan didalam minyak) di atas penangas air pada suhu $60-80{ }^{\circ} \mathrm{C}$ selama 5 menit, kemudian ditambahkan $\mathrm{NaOH} 30 \%$ sampai terbentuk

Tabel 1. Formulasi sabun padat transparan yang diperkaya dengan ekstrak kasar karotenoid C. pyrenoidosa (Cognis, 2003 yang dimodifikasi)

Table 1. Transparent solid soap formulation enriched with carotenoid crude extract of C. pyrenoidosa (Cognis, 2003, modified)

\begin{tabular}{lcccc}
\hline \multicolumn{1}{c}{ Bahan/Ingredients } & \multicolumn{4}{c}{ Komposisi (b/b)/Composition (w/w) } \\
& Blanko/Blank & F1 & F2 & F3 \\
\hline Ekstrak karotenoid C. pyrenoidosa & - & $\mathbf{5 . 0 0}$ & $\mathbf{1 0 . 0 0}$ & $\mathbf{1 5 . 0 0}$ \\
Asam stearat/Stearic acid & 6.40 & 6.40 & 6.40 & 6.40 \\
Minyak kelapa/Coconut oil & 19.40 & 19.40 & 19.40 & 19.40 \\
Minyak zaitun/Olive oil & 6.00 & 6.00 & 6.00 & 6.00 \\
Minyak jarak/Castor oil & 6.00 & 6.00 & 6.00 & 6.00 \\
$\mathrm{NaOH} 30 \%$ & 19.40 & 19.40 & 19.40 & 19.40 \\
$\mathrm{NaCl}$ & 0.20 & 0.20 & 0.20 & 0.20 \\
Gliserin/Glycerin & 9.40 & 9.40 & 9.40 & 9.40 \\
Sukrosa 50\%/Sucrose 50\% & 13.40 & 13.40 & 13.40 & 13.40 \\
Etanol 96\%/Ethanol 96\% & 15.00 & 15.00 & 15.00 & 15.00 \\
Cocoamide DEA & 1.00 & 1.00 & 1.00 & 1.00 \\
Trietanolamine & 1.00 & 1.00 & 1.00 & 1.00 \\
Metil paraben/Methyl paraben & 0.15 & 0.15 & 0.15 & 0.15 \\
Butil hidroksitoluen/Butyl hydroxytoluen & 0.01 & 0.01 & 0.01 & 0.01 \\
Propil paraben/Propyl paraben & 0.03 & 0.03 & 0.03 & 0.03 \\
Lemon grass oil & $\mathrm{qs}$ & $\mathrm{qs}$ & $\mathrm{qs}$ & $\mathrm{qs}$ \\
Akuades/Aquades & 6.50 & 6.50 & 6.50 & 6.50 \\
\hline
\end{tabular}


massa kental yang menunjukkan terbentuknya massa sabun. Gliserin ditambahkan ke dalam campuran massa sabun, dan diaduk sampai homogen pada suhu

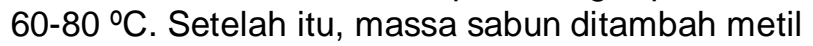
paraben dan propil paraben (yang telah dilarutkan dalam etanol $96 \%$ ) dan diaduk sampai homogen pada suhu $60^{\circ} \mathrm{C}$, kemudian sisa etanol dimasukkan dan diaduk sampai homogen. Ekstrak karotenoid mikroalga $C$. pyrenoidosa dimasukkan ke dalam campuran yang sudah terbentuk sambil terus diaduk sampai homogen. Selanjutnya dilakukan penambahan larutan sukrosa $50 \%, \mathrm{NaCl}$ dan akuades sampai homogen pada suhu $60^{\circ} \mathrm{C}$. Trietanolamin dan cocoamide DEA (yang telah dilarutkan dalam air) dimasukkan ke dalam campuran, diaduk sampai homogen. Lemon grass oil dimasukkan ke dalam campuran pada suhu $40^{\circ} \mathrm{C}$ dan diaduk sampai homogen. Campuran dituang ke dalam cetakan sabun dan didiamkan pada suhu kamar sampai mengeras. Sabun yang terbentuk selanjutnya dievaluasi yang meliputi sifat sensori, fisik, kimia dan stabilitasnya selama penyimpanan.

\section{Evaluasi sifat sensori, fisik dan kimia sabun padat transparan}

Parameter yang dievaluasi yaitu pemeriksaan organoleptik secara deskripsi terhadap kenampakan warna dan transparansi menggunakan Handbook of Colour (Kornerup \& Wanscher, 1963) serta aroma secara sensori. Evaluasi kekerasan sabun menggunakan alat penetrometer. Kadar air ditentukan dengan menggunakan metoda gravimetri. Pengujian asam lemak bebas atau alkali bebas dan uji asam lemak yang tidak tersabunkan mengacu pada Standar Nasional Indonesia sabun mandi (SNI 06-3532-1994). Pengujian aktivitas antioksidan dilakukan dengan metode peredaman radikal bebas (DPPH).

\section{Uji aktivitas antioksidan dengan metode peredaman radikal bebas DPPH}

Aktivitas antioksidan diuji dengan menggunakan metoda Brand-Williams dan Cuvelier (1995) dengan sedikit modifikasi. Ekstrak kasar karotenoid (25, 50, $125,250$ dan $500 \mu \mathrm{l})$ dan sabun transparan $(5 \%, 10 \%$ dan 15\%) ditambah masing-masing $1 \mathrm{ml}$ DPPH 0.4 $\mathrm{mM}$ dan dicukupkan volumenya hingga $5 \mathrm{ml}$ dengan metanol absolut sehingga diperoleh larutan dengan konsentrasi 5, 10, 25, 50 dan 100 ppm. Larutan blangko dibuat dengan cara menambahkan $1 \mathrm{ml} \mathrm{DPPH}$ $0,4 \mathrm{mM}$ dengan $4 \mathrm{ml}$ methanol absolut. Kontrol positif menggunakan vitamin $C$ dengan konsentrasi 2, 4, 6, 8 dan 10 ppm. Semua sampel dihomogenkan dan diinkubasi pada suhu $37^{\circ} \mathrm{C}$ selama 30 menit dan diukur serapannya pada spektrofotometer UV-VIS dengan panjang gelombang $517 \mathrm{~nm}$. Aktivitas antioksidan dihitung dengan rumus :

$$
\begin{gathered}
\% \text { Hambatan/ } \\
\text { Inhibition }
\end{gathered}=\frac{\begin{array}{c}
\text { Serapan blangko/ } \\
\text { Blank adsorption }
\end{array} \text { Sample adsorption }}{\text { Serapan blangko/ }} \times 100 \%
$$

Nilai $I C_{50}$ dihitung dengan menggunakan persamaa regresi linear dari DPPH yaitu $\mathrm{Y}=\mathrm{a}+\mathrm{bx}$, dengan sumbu $x$ adalah konsentrasi larutan uji sedangkan sumbu $Y$ adalah \% IC. Nilai $I_{50}$ (Inhibition Concentration 50\%) dinyatakan sebagai konsentrasi suatu bahan antioksidan yang dapat menyebabkan $50 \%$ radikal bebas DPPH kehilangan karakter radikal.

\section{Uji stabilitas sabun padat transparan}

Uji stabilitas dilakukan pada suhu $25-30 \stackrel{\circ}{ } \mathrm{C}$ dan $60{ }^{\circ} \mathrm{C}$ setiap minggu selama 3 minggu (mengacu pada Lachman, Lieberman, \& Kanig, 1994). Parameter yang dilakukan meliputi uji kekerasan sabun menggunakan alat penetrometer serta penentuan $\mathrm{pH}$ dan kadar air dengan metoda gravimetri pengeringan dalam oven suhu $105^{\circ} \mathrm{C}$ selama 1 jam (SNI, 1994).

\section{HASIL DAN BAHASAN}

\section{Ekstrak Kasar Karotenoid C. pyrenoidosa}

Metode ekstraksi yang digunakan dalam studi ini memberikan hasil berupa ekstrak cair berwarna orange yang terindikasi sebagai ekstrak kasar karotenoid. Persentase rendemen ekstrak kasar karotenoid yang didapat adalah 2,08 $\pm 0,01 \%$. Pada studi ini, identifikasi ekstrak kasar karotenoid dilakukan dengan melihat spektrum pigmen karotenoid menggunakan spektrofotometri UV-Vis pada panjang gelombang 400$700 \mathrm{~nm}$. Hasil yang diperoleh menunjukkan bahwa terdapat senyawa ekstrak kasar karotenoid pada serapan di 440-460 nm. Keberadaan puncak di 300$350 \mathrm{~nm}$ merupakan bukti tambahan keberadaan golongan oksigenasi yang diduga merupakan xantofil. Keberadaan klorofil terlihat juga pada spektra dengan serapan sekitar 600-700 nm (Gambar 1).

\section{Pembuatan Sabun Padat Transparan}

Hasil optimasi kecepatan dan waktu pengadukan pada proses pembuatan sabun padat transparan menunjukkan bahwa kecepatan sebesar $350 \mathrm{rpm}$ selama 20 menit merupakan hasil yang optimum dan menghasilkan sediaan sabun padat transparan yang homogen dan tidak berbusa selama proses pembuatan (Tabel 4). Semakin tinggi kecepatan pengadukan akan menimbulkan busa semakin banyak pada sediaan. 


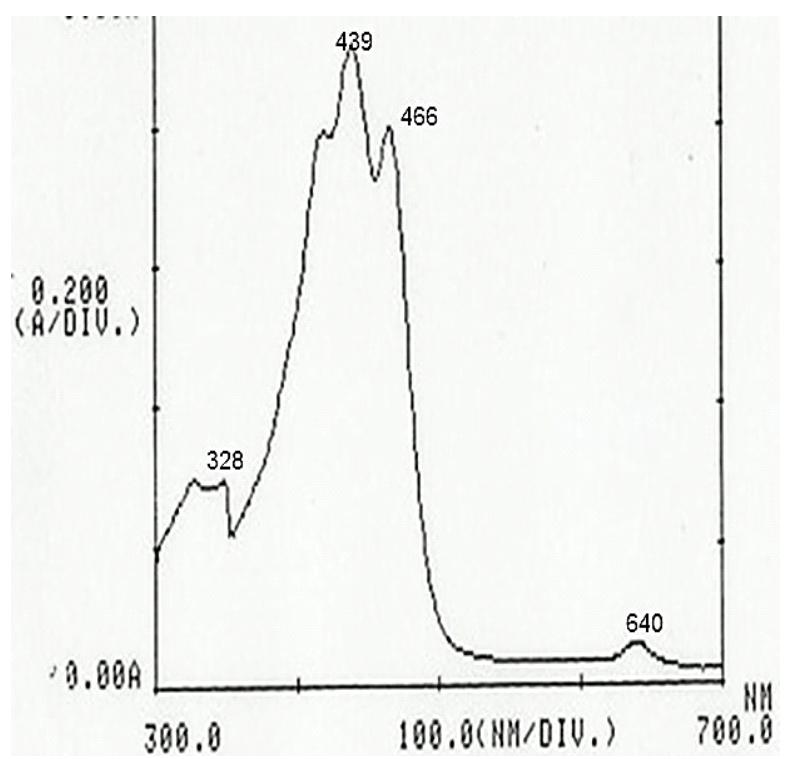

Gambar 1. Spektrum pigmen karotenoid mikroalga C. pyrenoidosa.

Figure 1. Spectrum of carotenoid from microalgae C. pyrenoidosa.

Timbulnya busa tidak hanya dipengaruhi oleh kecepatan dan waktu pengadukan saja, tetapi juga dipengaruhi oleh penambahan surfaktan. Surfaktan yang dilarutkan dalam air, bila terjadi kontak dengan udara dapat menyebabkan timbulnya busa. Oleh karena itu, saat pengadukan wadah pembuatan sabun harus tertutup untuk menghindari masuknya udara.
Sabun padat transparan yang dihasilkan dari formulasi ekstrak kasar karotenoid C. pyrenoidosa dapat dilihat pada Gambar 2. Berdasarkan indeks warna dari Handbook of Colour (Kornerup \& Wanscher, 1963), sabun padat transparan yang dihasilkan berwarna Neon Carrot untuk formulasi 1 yang mengandung ekstrak kasar karotenoid 5\%, Pizazz

Tabel 2. Optimasi kecepatan dan waktu pengadukan pada pembuatan sabun padat transparan

Table 2. Optimization of speed and time of stirring for the transparent solid soap

\begin{tabular}{|c|c|c|c|c|}
\hline $\begin{array}{l}\text { Kecepatan/ } \\
\text { speed (rpm) }\end{array}$ & $\begin{array}{c}\text { Waktu (menit)/ } \\
\text { time(minute) }\end{array}$ & $\begin{array}{l}\text { Transparan/ } \\
\text { transparent }\end{array}$ & $\begin{array}{c}\text { Kehomogenan/ } \\
\text { homogenety }\end{array}$ & $\begin{array}{l}\text { Busa/ } \\
\text { foam }\end{array}$ \\
\hline & 10 & $x$ & $\varnothing$ & - \\
\hline \multirow[t]{3}{*}{250} & 20 & $x$ & $\varnothing$ & - \\
\hline & 30 & * & $\varnothing$ & ++ \\
\hline & 10 & * & $\varnothing$ & - \\
\hline \multirow[t]{3}{*}{350} & 20 & * & 0 & - \\
\hline & 30 & * & 0 & + \\
\hline & 10 & * & 0 & + \\
\hline \multirow[t]{2}{*}{400} & 20 & * & 0 & ++ \\
\hline & 30 & * & 0 & ++ \\
\hline
\end{tabular}

\section{Keterangan/note :}

$\varnothing=$ Tidak homogen/Not homogen

$\mathrm{O}=$ Homogen/Homogen

++ = Banyak busa/More quantity of foam $x=$ Tidak transparan/Not transparent

* = Transparan/Transparent
= Tidak berbusa/Not produced foam

$+\quad=$ Berbusa/Produce foam 
Gambar 2. Spesifikasi warna sabun padat transparan yang mengandung ekstrak kasar karotenoid dari $C$. pyrenoidosa

Figure 2. Colour specification of transparent solid soap containing carotenoid crude extract from $\underline{C}$. pyrenoidosa

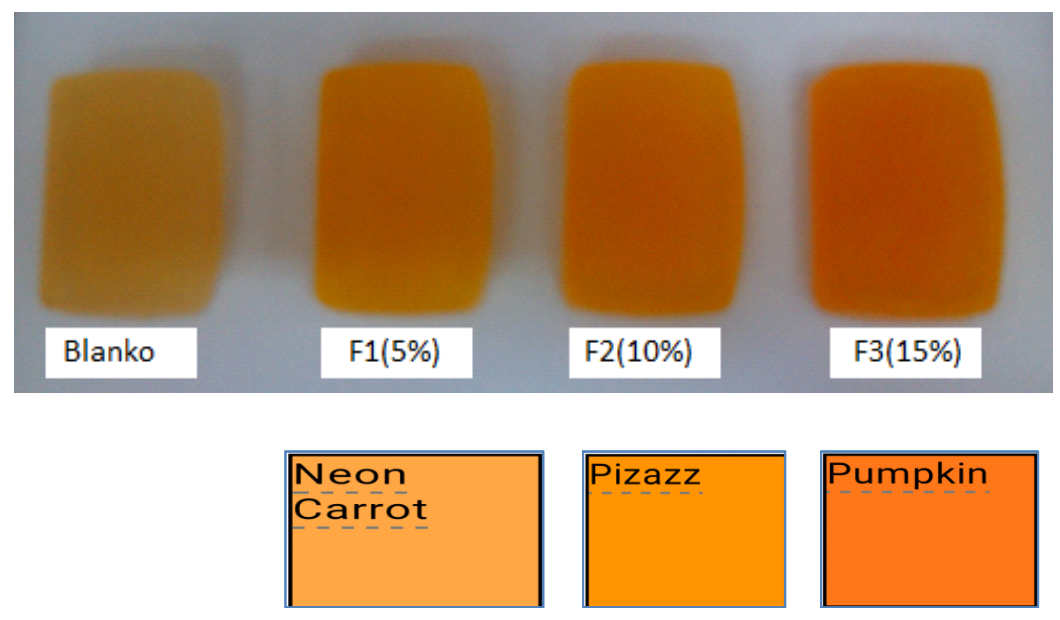

untuk formulasi 2 dengan ekstrak karotenoid $10 \%$ dan Pumpkin untuk formulasi 3 dengan ekstrak kasar karotenoid $15 \%$. Warna yang dihasilkan pada sabun transparan berasal dari warna esktrak kasar karotenoid mikroalga $C$. pyrenoidosa.

\section{Evaluasi Sabun Padat Transparan}

\section{Sifat sensori}

Hasil pengamatan organoleptik menunjukkan bahwa, sabun yang dihasilkan memiliki bentuk padat dan transparan dengan warna kuning neon carrot $(5 \%)$, kuning pizzaz (10\%) dan kuning pumpkin (15\%). Aroma khas yang ditimbulkan adalah aroma lemongrass yang memberikan kesegaran dalam tubuh (Tabel 3)

\section{Sifat fisik dan kimia}

Sifat fisik yang diamati pada sabun ini adalah kekerasan sabun. Uji kekerasan sabun padat transparan dengan menggunakan alat penetrometer menunjukkan bahwa semakin kecil nilai penetrasi jarum ke dalam sabun berarti sabun yang dihasilkan semakin keras dan sebaliknya semakin besar nilai penetrasi jarum ke dalam sabun berarti semakin lunak sabun yang dihasilkan. Persyaratan nilai kekerasan sabun padat transparan belum tersedia, sehingga digunakan pembanding yaitu sabun padat transparan

Tabel 3. Deskripsi sifat sensori sabun padat transparan yang mengandung ekstrak karotenoid $C$. pyrenoidosa. Table 3. Sensory description of transparent solid soap containing carotenoid extract from C. pyrenoidosa

\begin{tabular}{|c|c|c|c|}
\hline \multirow{2}{*}{ Formula/Formula } & \multicolumn{3}{|c|}{ Parameter/Parameter } \\
\hline & Warna/Color & Aroma/Aroma & Tekstur/Textur \\
\hline Blangko/Blank & $\begin{array}{l}\text { Putih kekuningan/Yellowish white, } \\
\text { transparan/transparent }\end{array}$ & Lemongrass & Padat/Solid \\
\hline $1(5 \%)$ & $\begin{array}{l}\text { Kuning neon carrot/Yellow neon } \\
\text { carrot, transparan/transparent }\end{array}$ & Lemongrass & Padat/Solid \\
\hline $2(10 \%)$ & $\begin{array}{l}\text { Kuning pizzas/Yellow pizzas, } \\
\text { transparan/transparent }\end{array}$ & Lemongrass & Padat/Solid \\
\hline $3(15 \%)$ & $\begin{array}{c}\text { Kuning pumpkin/Yellow pumpkin, } \\
\text { transparan/transparent }\end{array}$ & Lemongrass & Padat/Solid \\
\hline
\end{tabular}


komersial, yang memiliki nilai kekerasan 1,04- 2,40 $\mathrm{mm} /$ detik. Nilai kekerasan sabun transparan pada semua formulasi yang dibuat berkisar 1,40-1,80 mm/ detik (Tabel 4). Hal ini menunjukkan bahwa, nilai kekerasan sabun padat transparan ekstrak kasar karotenoid dari mikroalga $C$. pyrenoidosa memenuhi kriteria sabunkomersial. Pada Tabel 4 juga terlihat bahwa nilai kekerasan sabun semakin meningkat (sabun semakin lunak) seiring dengan meningkatnya konsentrasi ekstrak kasar karotenoid. Hal ini disebabkan ekstrak kasar karotenoid mudah menyatu dengan air (Sulistiani, Pramulani, \& Yati, 2009).

Kadar air dalam sabun padat berpengaruh terhadap kualitas sediaan. Air yang ditambahkan dalam produk sabun dapat mempengaruhi kelarutan sabun dalam air. Semakin banyak air yang terkandung dalam sabun, maka sabun akan mudah menyusut dan cepat habis pada saat digunakan (Hambali, Bunasor, Suryani, \& Kusumah, 2005). Pada Tabel 4, terlihat kadar air dalam sabun padat transparan yang mengandung ekstrak kasar karotenoid berkisar 14,45$16,28 \%$ sedangkan kadar air sabun yang tidak mengandung ekstrak karotenoid adalah 10,41. Menurut SNI (1994), persyaratan kadar air pada sabun padat transparan tidak lebih dari $15 \%$. Dengan demikian formula 1 dan 2 memenuhi persyaratan, sedangkan formula 3 melewati persyaratan. Meningkatnya persentase kadar air seiring dengan meningkatnya penambahan ekstrak pigmen karotenoid. Hal ini karena karotenoid pigmen yang mengandung air sehingga menambah ekstrak kasar karoternoid berarti memberikan tambahan kandungan air pada sabun tersebut.
Syarat standar mutu $\mathrm{pH}$ untuk sabun mandi berkisar antara 9-11 (SNI, 1994). Pada Tabel 4. pH sediaan sabun padat transparan berkisar antara 9,31\%- 10,47\%. Kisaran nilai pH ini memenuhi kriteria mutu sabun mandi. Nilai $\mathrm{pH}$ mempunyai kecenderungan menurun seiring dengan penambahan ekstrak kasar karotenoid yang mempunyai pH 6-7. Menurut Munson (1991), sabun yang memiliki pH terlalu tinggi dapat meningkatkan daya absorpsi kulit, sehingga kulit menjadi gatal atau mengelupas dan dapat menyebabkan kulit kering.

Asam lemak bebas berasal dari asam lemak yang tidak terikat dengan natrium ataupun trigliserida. Kadar asam lemak tidak boleh terlalu tinggi karena akan memicu ketengikan dan mengurangi umur simpan sabun (Khopkar, 1990). Dalam suatu formulasi, asam lemak berperan sebagai pengatur konsistensi. Spitz (1996) menyatakan bahwa asam lemak memiliki kemampuan terbatas untuk larut dalam air. Hal ini akan membuat sabun menjadi lebih tahan lama setelah digunakan. Hasil pemeriksaan asam lemak bebas sabun padat transparan berkisar antara 0,420,79\% (Tabel 4). Pesyaratan asam lemak bebas dalam sabun padat transparan $<2,5 \%$ (SNI, 1994) sehingga semua sabun padat transparan ekstrak kasar karotenoid C. pyrenoidosa memenuhi pesyaratan.

Lemak tidak tersabunkan merupakan lemak yang tidak ikut bereaksi selama proses saponifikasi, apabila nilai lemak tidak tersabunkan tinggi akan menimbulkan kurangnya busa yang dihasilkan oleh sabun (Khopkar, 1990). Fraksi yang tidak tersabunkan berkaitan dengan zat-zat terdapat dalam minyak atau

Tabel 4. Sifat fisik dan kimia sabun padat transparan yang mengandung ekstrak kasar karotenoid dari $C$. pyrenoidosa.

Table 4. Physical and chemical characteristics of transparent solid soap containing carotenoid crude extract from C. pyrenoidosa

\begin{tabular}{|c|c|c|c|c|c|}
\hline \multirow[b]{2}{*}{$\begin{array}{l}\text { Formula/ } \\
\text { Formula }\end{array}$} & \multicolumn{5}{|c|}{ Rata-rata/average } \\
\hline & $\begin{array}{c}\text { Kekerasan } \\
\text { sabun } \\
\text { (mm/detik)/Hard } \\
\text { ness of soap } \\
(\mathrm{mm} / \mathrm{second})\end{array}$ & pH & $\begin{array}{l}\text { Kadar air/ } \\
\text { Moisture } \\
\text { content (\%) }\end{array}$ & $\begin{array}{c}\text { Asam lemak } \\
\text { bebas/ } \\
\text { Free fatty acid } \\
\text { (\%) }\end{array}$ & $\begin{array}{c}\text { Lemak tidak } \\
\text { tersabunkan/ } \\
\text { Fat No } \\
\text { saponified (\%) }\end{array}$ \\
\hline Blangko/Blank & $1.4 \pm 0.01$ & $10.76 \pm 0.01$ & $10.41 \pm 0.16$ & $0.79 \pm 0.02$ & $1.79 \pm 0.07$ \\
\hline $1(5 \%)$ & $1.4 \pm 0.01$ & $10.47 \pm 0.03$ & $14.45 \pm 0.22$ & $0.63 \pm 0.02$ & $1.78 \pm 0.07$ \\
\hline $2(10 \%)$ & $1.8 \pm 0.01$ & $9.66 \pm 0.02$ & $14.59 \pm 0.23$ & $0.68 \pm 0.04$ & $1.84 \pm 0.09$ \\
\hline $3(15 \%)$ & $1.8 \pm 0.02$ & $9.31 \pm 0.03$ & $16.28 \pm 0.75$ & $0.42 \pm 0.02$ & $1.79 \pm 0.08$ \\
\hline SNI & - & $9-11$ & $<15$ & $<2.5$ & $<2$ \\
\hline
\end{tabular}


lemak yang tak tersabunkan. Zat-zat tersebut biasanya berupa sterol dan hidrokarbon (Hernani, Bunasor, \& Fitriati, 2010). Pada Tabel 4. kandungan lemak tidak tersabunkan pada semua formulasi sabun transparan berkisar antara 1,78-1,84\%. Menurut SNI (2016), persyaratan asam lemak tidak tersabunkan maksimal $2 \%$ sehingga sabun padat transparan dengan penambahan ekstrak kasar karotenoid 5\%, $10 \%$ dan $15 \%$ memenuhi persyaratan.

\section{Uji Antioksidan dengan Metode Peredaman Radikal Bebas (DPPH)}

Hasil pengujian ekstrak kasar karotenoid menunjukkan nilai $\mathrm{IC}_{50}$ sebesar $58,181 \mu \mathrm{g} / \mathrm{ml}$ (Tabel 5). Hal ini menunjukkan bahwa ekstrak kasar karotenoid dari mikroalga $C$. pyrenoidosa memiliki aktivitas antioksidan kuat. Menurut Koleva et al. (2002), senyawa yang memiliki nilai $\mathrm{IC}_{50}$ kurang dari $100 \mu \mathrm{g} / \mathrm{ml}$ memiliki sifat antioksidan yang kuat. Sementara itu, vitamin $\mathrm{C}$ yang digunakan sebagai kontrol memiliki aktivitas antioksidan sebesar 1,62 $\mathrm{gg} /$ $\mathrm{ml}$ dengan kategori yang sangat kuat.

Di samping itu, pada Tabel 5 juga terlihat bahwa sediaan sabun padat transparan dari semua formula memiliki aktivitas antioksidan. Formulasi blangko memiliki nilai $I_{50}$ sebesar $126 \mu \mathrm{g} / \mathrm{mL}$. Hal ini kemungkinan disebabkan oleh adanya penambahan BHT (Butil Hidroksitoluen) yang merupakan antioksidan sintetik. Fungsi BHT dalam formulasi sabun padat adalah untuk menjaga agar minyak dalam sabun tidak teroksidasi yang akan menyebabkan ketengikan. Nemat Shahi et al. (2016) mengemukakan bahwa ketengikan terjadi karena dalam minyak terdapat ikatan rangkap sehingga akan menyebabkan terbentuknya asam, aldehid, dan keton dengan rantai pendek yang akan menimbulkan bau dan cita rasa tengik.
Dengan demikian sabun padat trasnparan dengan formula 1 dan 2 memiliki aktivitas antioksidan yang kuat, sedangkan formula 3 memiliki aktivitas antioksidan sangat kuat. Data yag diperoleh menunjukkan bahwa semakin meningkat ekstrak karotenoid yang digunakan, maka semakin kuat aktivitas antioksidan yang dihasilkan. Menurut Koleva, et al. 2002 aktivitas antioksidan dengan nilai $\mathrm{IC}_{50} 50$ $100 \mu \mathrm{g} / \mathrm{ml}$ termasuk katagori kuat dan nilai $\mathrm{IC}_{50}<50$ $\mu \mathrm{g} / \mathrm{ml}$ katagori sangat kuat.

Menurut Ambati, Phang, Ravi dan Aswathanarayana (2013), astaxanthin dari $H$. pluvialis memiliki bioavailabilitas yang lebih baik dan sifat antioksidan yang lebih baik dibandingkan dengan karotenoid lain. Sementara itu, Cerón et al. (2007) berpendapat bahwa aktivitas antioksidan astaxanthin secara in vitro terhadap DPPH 10 kali lebih tinggi dari $\beta$-karoten dan 500 kali lebih tinggi dari a-tokoferol. Oleh karena itu, semakin tinggi ekstrak kasar karotenoid yang ditambahkan ke dalam formula sabun transparan maka semakin tinggi aktivitas antioksidannya.

\section{Uji Stabilitas Sabun Padat Transparan}

Stabilitas sabun padat transparan dapat dilihat setelah penyimpanan produk selama waktu simpannya (shelf-life). Namun demikian, cara ini membutuhkan waktu yang lama sedangkan siklus pengembangan produk kosmetik relatif singkat, sehingga digunakan pengujian stabilitas dipercepat untuk memperkirakan stabilitas jangka panjang. Uji stabilitas dipercepat adalah uji yang dirancang untuk meningkatkan laju degradasi kimia dan perubahan fisika suatu sediaan dengan membuat suatu kondisi penyimpanan yang dilebihkan. Menurut CTFA (2004) uji stabilitas dipercepat dilakukan untuk memprediksikan seberapa jauh produk tahan terhadap tekanan dan temperatur ekstrim. Tujuan uji stabilitas

Tabel 5. Nilai $I C_{50}$ ekstrak kasar karotenoid, blangko, vitamin $\mathrm{C}$ dan sabun padat transparan yang mengandung ekstrak kasar karotenoid $C$. pyrenoidosa

Table 5. The $I C_{50}$ value of carotenoid crude extract, blank, vitamin $C$ and transparent solid soap containing carotenoid crude extract from C. pyrenoidosa

\begin{tabular}{lc}
\hline \multicolumn{1}{c}{ Sampel/Sample } & IC $_{50}(\mu \mathrm{g} / \mathrm{ml})$ \\
\hline Blangko/Blank & 126.00 \\
Formula 1/Formula 1 & 66.42 \\
Formula 2/Formula 2 & 59.18 \\
Formula 3/Formula 3 & 10.21 \\
Ekstrak kasar Karotenoid/Carotenoid crude extract & 58.18 \\
Vitamin C/Vitamin C & 1.62 \\
\hline
\end{tabular}


untuk menentukan parameter kinetik sehingga waktu kadaluarsa dapat diprediksi. Pada studi ini, uji stabilitas dipercepat dilakukan dengan cara teknik manipulasi suhu yang dilakukan selama 3 minggu (Lachman et al., 1994).

\section{Kekerasan sabun}

Penambahan ekstrak kasar karotenoid pada sabun padat ternyata mempengaruhi kekerasan sabun (Gambar 3). Semakin tinggi konsentrasi ekstrak kasar karotenoid yang ditambahkan maka nilai kekerasan sabun atau nilai penetrasi jarum kedalam sabun semakin tinggi yang berarti sabun akan semakin lunak. Hal ini sesuai dengan penelitian yang dilakukan oleh Hernani et. al. (2010), bahwa semakin tinggi konsentrasi ekstrak lengkuas yang ditambahkan maka kekerasan sabun akan melunak. Uji stabilitas terhadap kekerasan menunjukkan bahwa kekerasan sabun padat transparan pada suhu kamar $\left(25-30^{\circ} \mathrm{C}\right)$ relatif tidak mengalami perubahan sedangkan pada suhu $60 \stackrel{\circ}{ } \mathrm{C}$ mengalami perubahan kekerasan. Pengaruh kekerasan pada sabun dapat disebabkan karena kadar air dalam sabun yang terus menyusut akibat adanya penguapan sehingga sabun lebih keras.

Persyaratan nilai kekerasan sabun belum tersedia sehingga tidak ada persyaratan yang menunjukkan kekerasan dalam sabun. Oleh karena itu, sabun pembanding digunakan sebagai acuan. Pada penelitian ini digunakan 3 sabun transparan komersial sebagai pembanding yang memiliki tingkat kekerasan yang berbeda. Hasil uji stabilitas selama 3 minggu menunjukkan bahwa sabun formula 1, 2 dan 3 yang disimpan pada suhu kamar $\left(25-30^{\circ} \mathrm{C}\right)$ mengalami kenaikan tingkat kekerasan sabun berkisar 1,43\%$3,4 \%$. Hal yang sama juga terjadi pada sabun pembanding yang mengalami tingkat kekerasan sabun antara 1,25\%-3,8\%. Hasil pengamatan pada suhu 60 ${ }^{\circ} \mathrm{C}$ menunjukkan bahwa kenaikan tingkat kekerasan pada sabun formula 1, 2 dan 3 berkisar antara 26,4-

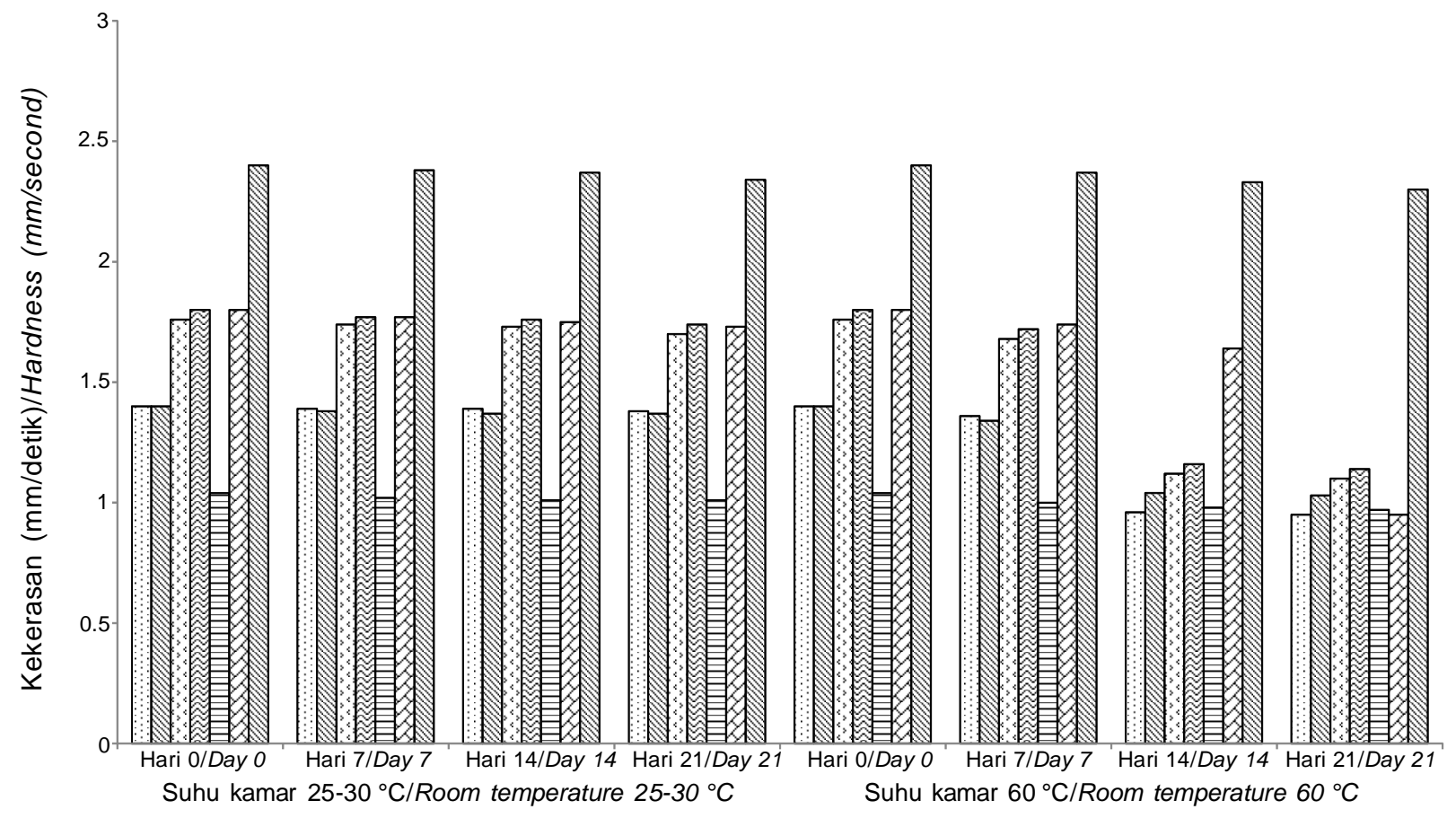

kamar $25-30{ }^{\circ} \mathrm{C} /$ Room temperature $25-30^{\circ} \mathrm{C}$

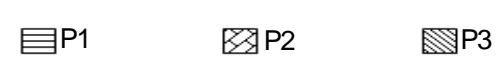

Perlakuan/Treatments

Keterangan/note :

$\begin{array}{ll}1,2,3,4 & =\text { Suhu/Temperature } 25-30{ }^{\circ} \mathrm{C} \\ \mathrm{B} & =\text { Blangko/Blank } \\ \mathrm{F} 1 & =\text { Formula/Formula } 1(5 \%) \\ \mathrm{F} 2 & =\text { Formula/Formula } 2(10 \%) \\ \mathrm{F} 3 & =\text { Formula/Formula } 3(15 \%)\end{array}$

$5,6,7,8=$ Suhu $/$ Temperature $60^{\circ} \mathrm{C}$

$\mathrm{P} 1=$ Pembanding $/$ Comparison 1

P2 = Pembanding $/$ Comparison 2

$\mathrm{P} 3=$ Pembanding $/$ Comparison 3

Gambar 3. Kekerasan sabun pada suhu kamar $\left(25-30^{\circ} \mathrm{C}\right)$ dan suhu $60^{\circ} \mathrm{C}$

Figure 3. The soap hardness at room temperature $\left(25-30^{\circ} \mathrm{C}\right)$ and temperature of $60^{\circ} \mathrm{C}$ 
$32,1 \%$ dan pada sabun pembanding berkisar antara 36-47\%. Kenaikan kekerasan sabun atau penurunan nilai kekerasan yang terdapat pada alat penetrometer menunjukkan bahwa kadar air dalam sabun terus menyusut sehingga sabun menjadi lebih keras. Berdasarkan hasil tersebut maka sabun berformula karotenoid 5\%, 10\% dan 15\% memiliki kekerasan sesuai dengan kriteria dengan sabun komersial (Gambar 3).

\section{Nilai pH}

Hasil pemeriksaan terhadap $\mathrm{pH}$ sabun padat transparan pada formula 1, 2 dan 3 pada suhu kamar $\left(25-30^{\circ} \mathrm{C}\right)$ setelah 21 hari relatif tidak mengalami perubahan yaitu berkisar antara 9,25 $\pm 0,01-$ $10,54 \pm 0,01$. Demikian pula halnya pada suhu $60^{\circ} \mathrm{C}$, setelah 21 hari pengamatan $\mathrm{pH}$ sabun tidak mengalami perubahan yaitu berkisar 9,23 $\pm 0,09$ $10,52 \pm 0,01$. Nilai $\mathrm{pH}$ yang diperoleh masih dalam persyaratan $\mathrm{pH}$ sabun padat transparan yaitu 9-11 sehingga sabun padat transparan stabil dalam penyimpanan (Gambar 4).

\section{Kadar air}

Analisa kadar air dilakukan untuk mengetahui kadar air dan zat yang menguap yang terdapat di dalam sabun. Pengukuran kadar air dan zat menguap perlu dilakukan karena akan berpengaruh terhadap kualitas sabun. Banyaknya air yang ditambahkan pada produk sabun akan mempengaruhi kelarutan sabun (Hambali et al., 2005). Menurut SNI (1994), persyaratan kadar air pada sabun padat transparan tidak lebih dari $15 \%$.

Kadar air pada uji stabilitas penyimpanan suhu kamar $\left(25-30^{\circ} \mathrm{C}\right)$ dan suhu $60^{\circ} \mathrm{C}$ berubah seiring dengan bertambahnya hari pengamatan (Gambar 5). Setelah 21 hari pengamatan, sabun trasnparan formula 1 dan 2 memiliki kadar air sebesar $14,05 \% \pm 0,01$ dan $14,11 \% \pm 0,01$. Berdasarkan hasil tersebut, sabun formula 1 dan 2 memenuhi persyaratan baku mutu sabun padat (SNI, 1994), sedangkan formula 3 memiliki kadar air yang tinggi (>15\%) yaitu $15,81 \% \pm 0,00$ sehigga tidak memenuhi persyaratan.

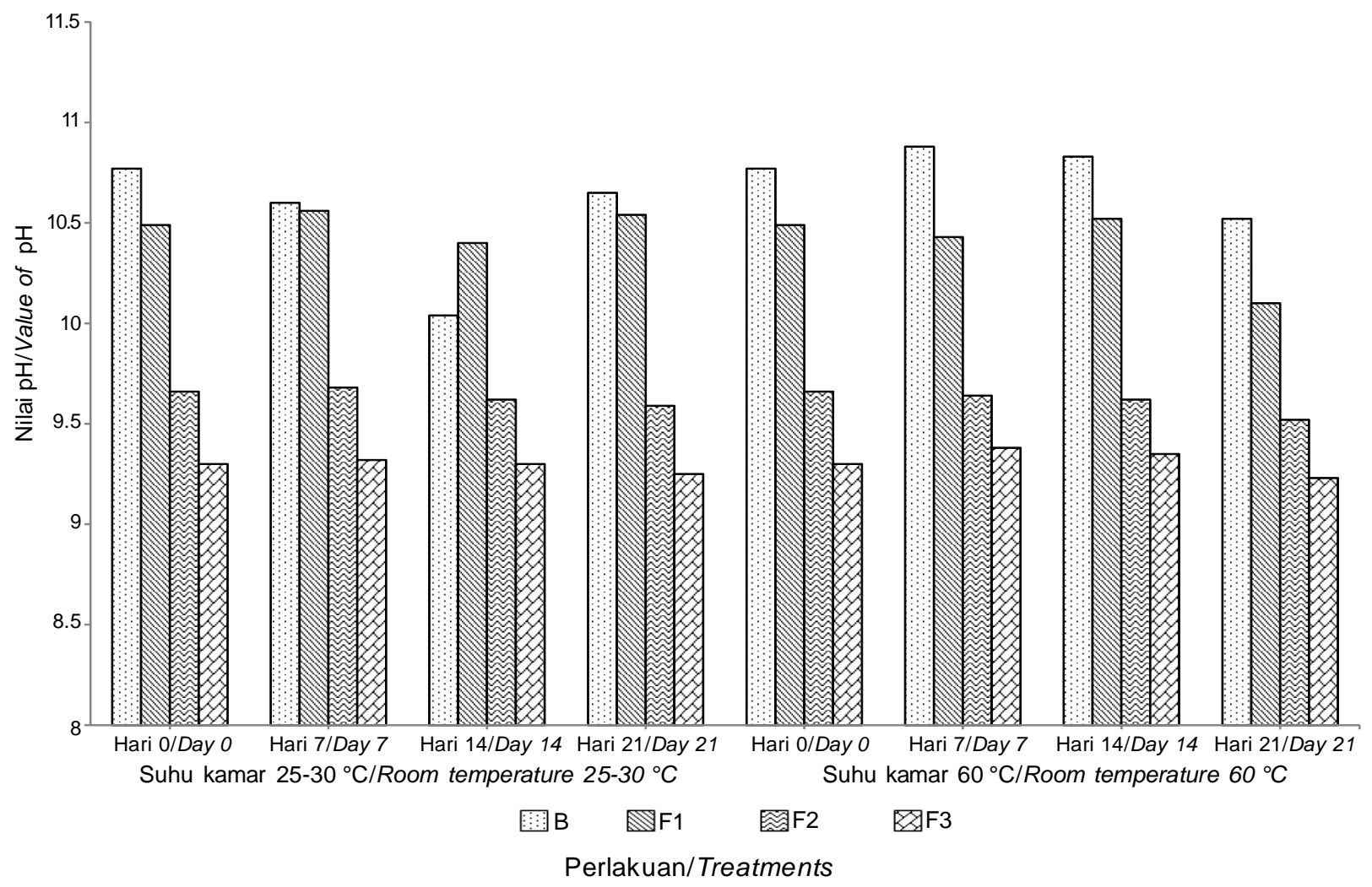

Keterangan :

$\mathrm{B}=$ blangko/Blank

F3 = Formula/Formula 3 (15\%)

$\mathrm{F} 1$ = Formula/Formula 1 (5\%)

$\mathrm{F} 2$ = Formula/Formula $2(10 \%)$

Gambar 4. Nilai pH sabun padat transparan pada suhu kamar $\left(25-30^{\circ} \mathrm{C}\right)$ dan suhu $60^{\circ} \mathrm{C}$.

Figure 4. The $\mathrm{pH}$ value of transparent solid soap at room temperature $\left(25-30^{\circ} \mathrm{C}\right)$ and temperature of $60^{\circ} \mathrm{C}$ 


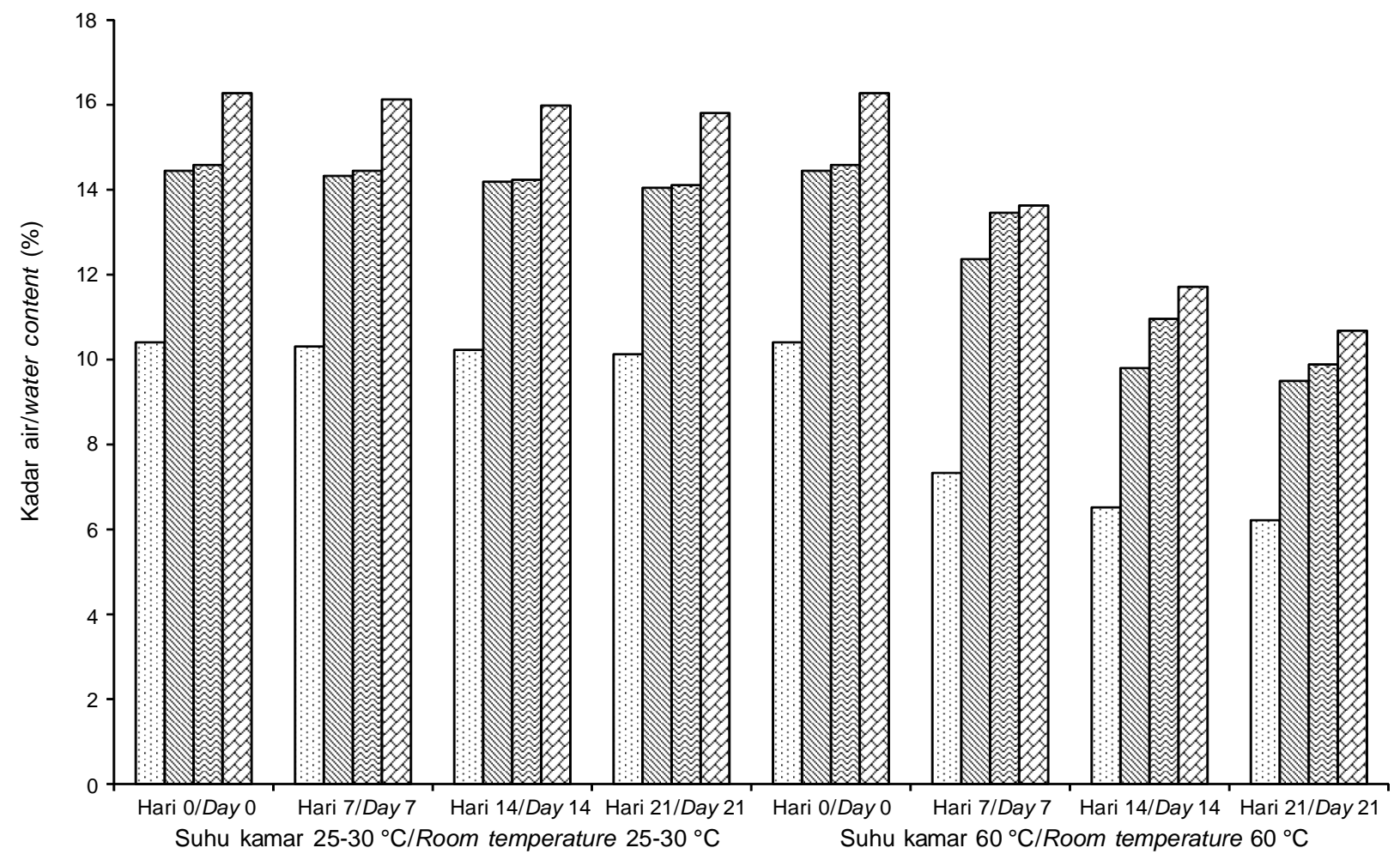

国 $\mathbb{B F}$ 图F2 四F3

Perlakuan/Treatments

Keterangan/note:

$\mathrm{B}=$ blangko/Blank

F2 = Formula/Formula 2 (10\%)

$$
\begin{aligned}
& \mathrm{F} 1=\text { Formula/ Formula } 1(5 \%) \\
& F 3=\text { Formula/Formula } 3(15 \%)
\end{aligned}
$$

Gambar 5. Kadar air sabun padat transparan pada suhu kamar $\left(25-30^{\circ} \mathrm{C}\right)$ dan suhu $60^{\circ} \mathrm{C}$.

Figure 5. The moisture content of transparent solid soap at room temperature $\left(25-30^{\circ} \mathrm{C}\right)$ and termperature at $60^{\circ} \mathrm{C}$

Uji stabilitas sabun padat transparan pada suhu $60^{\circ} \mathrm{C}$ formula 1 sampai 3 setelah hari ke 21 memiliki kadar air berkisar 6,22\% $\pm 0,01-10,68 \% \pm 0,02$. Menurunnya kadar air pada suhu $60^{\circ} \mathrm{C}$ disebabkan adanya penguapan air karena penyimpanan suhu yang relatif tinggi. Penurunan kadar air mengakibatkan nilai kekerasan sabun semakin kecil, hal ini berarti sabun menjadi semakin keras. Berdasarkan hasil uji stabilitas dipercepat, penyimpanan sabun pada suhu $60^{\circ} \mathrm{C}$ selama tiga minggu menunjukkan sabun stabil selama pengujian suhu dipercepat tersebut, sehingga diperkirakan sabun tahan dalam suhu kamar selama 2 tahun (Lachman et al., 1994). Uji stabilitas ini memberikan indikasi bahwa sabun padat transparan dengan tambahan ekstrak kasar karotenoid dengan sifat antioksidannya dapat direkomendasikan sebagai alternatif tambahan variasi produk kosmetika.

\section{KESIMPULAN}

Ekstrak kasar karotenoid yang bersumber dari mikroalga $C$. pyrenoidosa dalam formulasi sabun padat transparan mempunyai aktivitas antioksidan. Sabun padat transparan yang dihasilkan mempunyai karakteristik transparan, berwarna kuning neon carrot, kuning pizzaz dan kuning pumpkin, serta beraroma lemongrass. Nilai $\mathrm{pH}$, kekerasan sabun, kadar air, jumlah asam lemak bebas dan lemak tidak tersabunkan memenuhi persyaratan mutu sebagai sabun mandi sesuai dengan SNI 3532-1994. Sediaan sabun padat transparan berformulasi ekstrak kasar karotenoid dari mikroalga Chlorella pyrenoidosa stabil dalam penyimpanan suhu kamar selama 2 tahun karena sabun relatif stabil pada penyimpanan suhu $60^{\circ} \mathrm{C}$ selama 3 minggu. 


\section{DAFTAR PUSTAKA}

Agustini, N. W. S., \& Kabinawa, I. N. K. (1997). Pengaruh Penambahan Nitrogen Terhadap Produksi Biomasa dan Pigmen Chlorella pyrenoidosa dalam Skala Laboratorium. Seminar Nasional Bioteknologi Mikroalga. Puslitbang Bioteknologi-LIPI. 151-160.

Ambati, R. R., Phang, S. M. , Ravi, S. , \& Aswathanarayana R. G. (2014). Astaxanthin: Sources, Extraction, Stability, Biological Activities and Its Commercial Applications. Mar. Drugs , 12, 128-152; doi:10.3390/ md12010128

Becker, E. W. (1994). Microalgae Biotechnology and Microbiology. New York. Cambridge University Press. 56.

Brand-Williams, W. Cuvelier, M. E., \& Berset, C. (1995). Use of a free radical method to evaluate antioxidant activity. LWT-Food Science and Technology, 28,(1). 25-30

Brewer, M.S., (2011). Comprehensive review in food science and food safety. Institute of food technologists. Isuue 4 Version og record online 14 Juni 2011. Doi : 10.1111/j.1541-4337.2011.00156x

Cerón M.C., García-Malea, M. C., Rivas, J., Acien, F. G., Fernandez, J. M., Del Río, E., Guerrero, M.G., \& Molina, E. (2007). Antioxidant activity of Haematococcus pluvialis cells grown in continuous culture as a function of their carotenoid and fatty acid content. Appl Microbiol Biot., 74,1112-1119

Cognis. (2003). Clear Bar Soap Formulation. No: GWH 96/25. Care Chemical Division PT. Cognis Indonesia. Jakarta.

(CTFA).Cosmetic Toiletry and Fragrance Association. (2004). Guidelines on Stability Testing of Cosmetic Product, Washington DC).

Goiris, K., Muylaert, K., Fraeye, I., Foubert, I., de Brabanter, J., \& de Cooman, L. (2012). Antioxidant Potential of Microalgae in Relation to Their Phenolic and Carotenoid Content. J. Appl. Phycol. ,24,1477-1486. doi: 10.1007/s10811-012-9804-6.

Green, G. A. (2008). Review: antioxidant supplements do not reduce all-cause mortality in primary or secondary prevention. Evidence-Based Medicine, 13 (6): 177, doi:10.1136/ebm.13.6.177).

Hambali, E. T. K., Bunasor, A. Suryani \& Kusumah, G. A. (2005). Aplikasi Dietanolamida Dari Asam Laurat Minyak Inti Sawit Pada Pembuatan Sabun Transparan. J. Tek. Ind. Pert., 15(2), 46-53

Hernani, Bunasor, K. T., \& Fitriati. (2010) . Formula Sabun Transparan antijamur dengan Bahan Aktif Ekstrak
Lengkuas (Alpinia galanga L. Swartz). Bul. Littro., 21(2), 192-205

Khopkar, S. M. (1990). Konsep Dasar Kimia Analitik, diterjemahkan oleh Saptoharjo A. dan Nurhadi A., Jakarta : UI Press. p.215-217.

Koleva, Van Beek, Linssen, de Groot, Evstatieva, Prakashh, Rigelhof, \& Miller. (2002). Antioxidant activity. New York : prentice- hall mc. Engelwood cliffs.

Kornerup, A., \& Wanscher, H. J. (1963). Handbook of colour. Meutheun Publishing.New York. 18.

Kusmiati, Agustini N. W. S., Tamat, S. R., \& Rawati, M. (2010). Ekstraksi dan Purifikasi Senyawa Lutein dari Mikrolaga Chlorella pyrenoidosa Galur Lokal INK.Jurnal Kimia Indonesia, 5, 30-34.

Lachman, L., Lieberman, A. H., \& Kanig, L. J., (1994) The Theori and Practise of Industrial Pharmacy. Lea\&Febiger 600. Washington Square, USA. 15301531

Hua-Bin, L., Jiang, Y., \& Cheng, F. (2002). Isolation and Purification of Lutein from the microalga Chlorella vulgaris by Extraction after saponification. Journal of Agricultural and Food Chemistry, 5(5),1070-1072

Nemat Shahi, M. M., Elhami Rad, A. H., Nemat Shahi, N., Pedram Nia, A., \& Estiri., H. (2016). Study Of Antioxidant Activity And Free Radical Scavenging Power Of Physalis Alkekengi Flower Extract. J Fundam Appl Sci., 8(2S), 547-557

Munson, J. W. (1991). Analisis Farmasi, diterjemahkan oleh Harjana, Surabaya, Airlangga University Press. 369-378

(SNI). Standar Nasional Indonesia. (1994). 06-35321994.Sabun Mandi. Badan Standarisasi Nasional, Jakarta,1-10.

Stephen Inbaraj, B., Chien, J. T., \& Chen, B. H. (2016). Improved high performance liquid chromatographic method for determination of carotenoids in the microalga Chlorella pyrenoidosa. Journal of Chromatography A.., 11029(1-2), 193-199.

Spitz, I., (1996). Soap and Detergent a Theorical and Practical Review. AOCS Press, Champain-Illionis, 2, 47-73.

Sulistiani, Pramulani M., \& Yati. K. (2009). Variasi Konsentrasi Kokamidopropil Betain sebagai Surfaktan terhadap Stabilitas Fisik Sabun Transparan Minyak Atsiri Daun Kemangi (Ocimum sanctum Lin). Fakultas Farmasi dan Sains Univ. Muhammadiyah Prof.Dr.Hamka : Jakarta. 